\title{
Improving Bridge Component Deterioration Forecasting Precision
}

Harold S. Kleywegt, P.Eng.

Managing Director, Keystone Bridge Management Corp.

\begin{abstract}
One of the biggest knowledge gaps in bridge asset management is reliable information on the deterioration rate of bridge components. The overwhelming need for bridge rehabilitation in North America demands good field information and reliable forecasting data to determine appropriate bridge management strategies. A novel approach to improving this information shortfall consists of characterizing a bridge and its components in terms of Depreciation, Defects, and Damage. Depreciation is a simple deterministic measure based on the age and deemed life expectancy of the component. Defects are undesirable but non-threatening component attributes not caused by normal depreciation and are field identified and quantified during inspection. Similarly, Damage is any transformation of a component to a structurally weaker condition. Confining bridge inspection quantities to the less subjective measures of Defects and Damage will yield an improved understanding of bridge component deterioration and, it is proposed that a more consistent bridge condition metric will evolve.
\end{abstract}

\section{INTRODUCTION}

The science of modeling bridge behavior is the foundation of bridge design. Equally, the science of modeling bridge deterioration is the foundation of bridge asset management. Bridge design engineering has been well served by continued advances in the science for several hundred years. The science of bridge asset management is still in its infancy. Thus there is still considerable room for fundamental improvements.

One of the biggest knowledge gaps in bridge asset management is reliable information on the deterioration rate of bridge components. This is despite a US National Bridge Inventory System that collects information on nearly 600,000 bridges, and sophisticated bridge management systems such as PONTIS ${ }^{\circledR}$. Solid statistical information is not sufficiently available to dependably assist in forecasting individual bridge component condition ten or more years into the future.

The overwhelming and immediate need for bridge rehabilitation in North America demands good field information and accurate, reliable forecasting data in order to determine the most appropriate bridge management strategies. Is the field intelligence obtained from bridge inspection appropriately focused to obtain the essential information for effective bridge management? Perhaps the current subjective approach to assessing bridge condition needs to be retooled to yield more precise performance metrics for bridge inventories.

Modeling bridge deterioration continues to be a formidable challenge. The parameters that affect deterioration are numerous and unique to every constituent element of a bridge. Improvements to the reliability of deterioration modeling are modest at best. Current North American bridge inspection practices may actually hinder our appreciation of bridge deterioration. This point is illustrated by examining some common bridge inspection practices in the USA and Canada. 


\section{NORTH AMERICAN PRACTICES}

\subsection{National Bridge Inventory System (NBIS)}

The United States requires every state to submit NBIS data for each of their bridges. In all approximately 600,000 bridges are rated in NBIS. The NBIS rating scale ranges from nine (9) being "Excellent" to zero (0) meaning a "Failed condition". A rating of six (6) corresponds to "Satisfactory condition" while a three (3) rating represents a "Serious condition". These ratings are utilized in formulas to equitably distribute federal funds in support of bridge rehabilitation and replacement among the various states. This very substantial repository of bridge data has yielded the best information to date on the health of the US bridge network, on a state by state and national basis. Yet even the information that is the basis for federal funding of bridges is suspect. This is eminently stated in a seminal research activity sponsored by the US Federal Highway Administration. (Moore et al. 2001) Three notable conclusions quoted directly from the report are:

- Ninety-five percent of the primary element Condition Ratings for individual bridges will vary within two rating points of the average. Similarly, only 68 percent of these ratings will vary within one rating point.

- Inspectors are hesitant to assign "low" or "high" Condition Ratings and, as a result, tend to be grouped toward the middle of the Condition Rating scale.

- The National Bridge Inspection Standards Condition Rating system definitions may not be refined enough to allow for reliable Routine Inspection results. In addition, with the exception of some bridge management software, Condition Rating values are generally not assigned through the use of a rational approach.

The first recommendation from the report strongly reinforces the necessity of changing the most fundamental component of the NBIS approach:

- The accuracy and reliability of Routine Inspections may be greatly increased by revising the Condition Rating system.

Returning to the notion of tracking bridge deterioration, it is clear from the above report that there is variability and inconsistency in the coding of NBIS ratings. Hence tracking the growth of deterioration on individual bridges is greatly hampered. Fortunately, on a national basis, the NBIS rating system is a reasonable representation of the condition of the US bridge network.

\subsection{PONTIS ${ }^{\circledR}$ Bridge Management System}

PONTIS $^{\circledR}$ is the most common bridge management software system employed in the US. It is utilized by 39 states, and has been exported overseas to several countries. (Johnson et al. 2006) PONTIS $^{\mathbb{R}}$ records the deterioration of a bridge element by apportioning that element into one or more of three to five condition states available. Bridge joints and bearings typically have three choices of condition state. Steel and reinforced concrete bridge elements usually have five condition state choices. Timber components are described with four condition states. The first condition state is always the most favourable, whereas the last condition state indicates the most advanced deterioration of that component.

A very typical 500 square metre bridge deck is offered here as an example of how Condition States are coded into PONTIS ${ }^{\circledR}$. After inspection the bridge deck could be rated as $40 \%$ and $60 \%$ in Condition States 3 and 4 respectively. What does this indicate? Following the AASHTO Guide for CoRe Elements (AASHTO 1997) the deck exhibits distress including “...patched areas and/or potholes or impending potholes exist". Condition State 3 means the deck has two to ten percent distress and Condition State 4 means the deck has $10 \%$ to $25 \%$ distress. Doing the math, it can be summarized the entire deck has between 34 and 95 square metres of distressed surface. In round numbers the implication is this example deck surface is $13 \%$ plus or minus $7 \%$ distressed. When one considers the opportunity for subjectivity in actually prorating the deck 
element among the five condition states, it is clear there is a huge potential variability in outcomes.

The above example demonstrates how an inspection approach implicit to most of the US states may lead to ambiguity. These ambiguous results are then the basis for calibrating sophisticated tools such as Markov Chain deterioration modeling. This may well explain a growing level of dissatisfaction among bridge managers with respect to current computerized bridge management systems. (Smith \& Silva Filho 2000)

\subsection{Ontario Experience}

The Ministry of Transportation Ontario (MTO) in Canada developed its own bridge management system in the late 1990's. (Thompson et al. 2003) This system known as OBMS meaning Ontario Bridge Management System was later modified by the developer and introduced to several other provinces in Canada. OBMS employs a severity-extent model for assessing bridge components. Each component when inspected is assessed in terms of the quantity of that component in each of four conditions, Excellent, Good, Fair and Poor. A comprehensive Ontario Structure Inspection Manual (MTO 2000) guides bridge inspectors in the proper interpretation of assigning the four conditions. Excellent is reserved for essentially new components. The interpretation of Good, Fair, and Poor as it applies to bridge component and material deterioration is fully explained in the manual.

A bridge inspection workshop was held in 2004 for MTO staff and consultant inspectors. (Kenedi, unpubl.) The purpose of the workshop was among other things, to achieve greater consistency in how staff inspected and rated bridge components. One of the most troublesome components is assessing the deck top element for asphalt covered decks. Hence additional emphasis was placed on this element during the classroom training. MTO staff were divided into six inspection teams of three to four personnel each and tasked with independently rating a bridge deck. The results are shown in Figure 1.

Despite specific training, ample time to inspect, and opportunity for consensus building within teams, there was considerable variation in the inspection outcomes. One team considered the deck $100 \%$ poor, whereas another team thought the deck mostly good. Fortunately three teams were almost like minded in assessing the deck nominally $50 \%$ each in fair and poor condition.

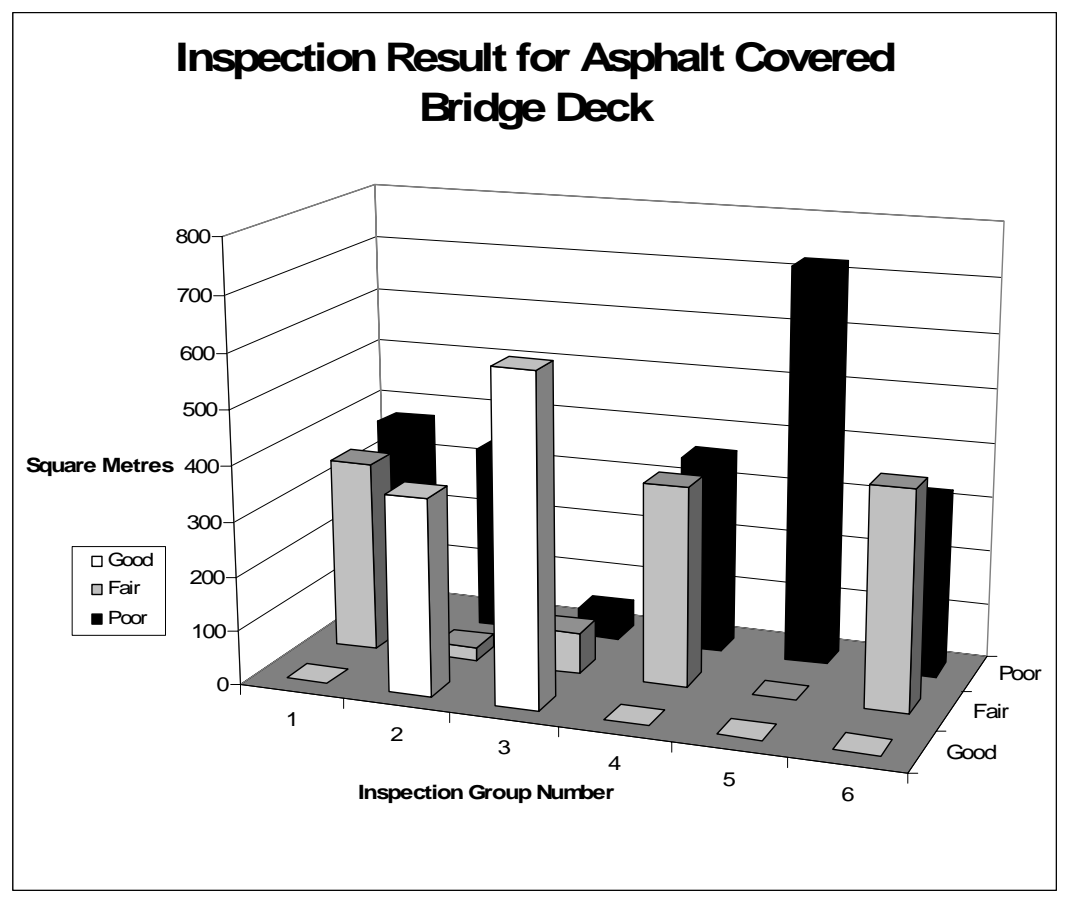

Figure 1. Variation in independent deck rating results by six different teams. 
The above experience amply demonstrates the opportunity for huge variance in interpretation when a subjective assessment of a bridge component is required. Is it realistically possible to achieve a sense of the rate of growth of bridge deterioration given this variability?

\section{PROPOSED NEW APPROACH}

A fundamental re-think of how bridges are modeled in an asset management system is in order. An innovative and fresh approach to modeling bridges is starting to be adopted in eastern Ontario, Canada. This new proprietary approach has been independently developed by the author.

The novel approach is termed "Triple-D". The three "D's" denote Depreciation, Defects and Damage. For asset management purposes a bridge is modeled by characterizing its components in terms of Depreciation, Defects, and Damage.

Depreciation is a simple deterministic measure based on the age and deemed life expectancy of the component. Depreciation describes the subtle changes in a bridge as it ages, such as carbonation of concrete and fatigue of structural steel. Depreciation is equally a financial measure of the deemed remaining worth of a bridge component. A fully Depreciated component may still be completely adequate to serve its intended function. However, given its Depreciated status there are some attendant risks. The primary risks are uncertainties with respect to remaining useful life, and structural capacity. Calculating Depreciation is a completely non-subjective desk top activity.

Defects are undesirable but non-threatening component attributes not caused by normal Depreciation. A Defect may also be defined as any unintended characteristic associated with the component material that does not have immediate structural consequences. Defects shorten the intended life of a component and/or hasten its Depreciation. Unattended Defects may grow and eventually result in Damage. Defects are field identified and quantified during regular bridge inspection. Typical examples of Defects are light to medium scaling of concrete and light surface rusting of structural steel that has lost its protection.

Similarly, Damage is any transformation of a component to a structurally weaker condition. Damage is any alteration of a material or component that results in loss of structural section, change of geometry, or degradation of performance. Damage may result from mechanical, chemical, biological, climatic or tectonic forces, fire, flood, settlement and the like. Damage is typically identified through routine inspection of the structure. Damage may be catastrophic as in a ship allision, or sublime as in decay of timber.

\section{ADVANTAGES}

\subsection{Depreciation}

From a bridge asset management perspective, there is only nominal value in knowing the "goodness" of a bridge. Yet in most bridge management systems there is considerable attention to assessing how much of a bridge is in Excellent or Good condition. There are complex and elaborate definitions explaining the subtleties of when a component transitions from Excellent to Good, or from Condition State 1 to 2, or from NBIS rating 9 to 6. Similarly the distinctions between Good and Fair, or Condition States 2 and 3 require lengthy definitions and burdensome manuals to cover all of the possibilities of bridge component deterioration.

The concept of Depreciation neatly dispenses with the requirement to rate the "goodness" of a bridge. The cataloguing of amount in Excellent or Good condition of a bridge component is replaced with the deterministic value of Depreciation. The Depreciation is calculated simply on the deemed life of the component, its actual age, and a characteristic function that models the Depreciation. The function can be a sloped line, parabola, or any other agreed mathematical model that suitably describes the relationship between Depreciation and time.

The following example data in Table 1 is utilized to develop the Depreciation curve in Figure 2. In this example, the bridge components are depreciated with a parabolic function following Equation 1 below: 


$$
\operatorname{Value}(t)=\operatorname{Value}(0) *\left[1-\left(t^{2} / \mathrm{L}^{2}\right)\right]
$$

where $t=$ time in years; Value $(0)$ is the original value; and $\mathrm{L}=$ the deemed life of the component in years.

Table 1. Example data for determining bridge Depreciation

\begin{tabular}{lll}
\hline Bridge Component & (L) Deemed Life (Years) & Relative Value in Bridge \\
\hline Deck & 40 & $30 \%$ \\
Expansion Joints & 20 & $5 \%$ \\
Bearings & 50 & $5 \%$ \\
Superstructure & 80 & $25 \%$ \\
Substructure & 100 & $25 \%$ \\
Railings & 30 & $10 \%$ \\
\hline
\end{tabular}

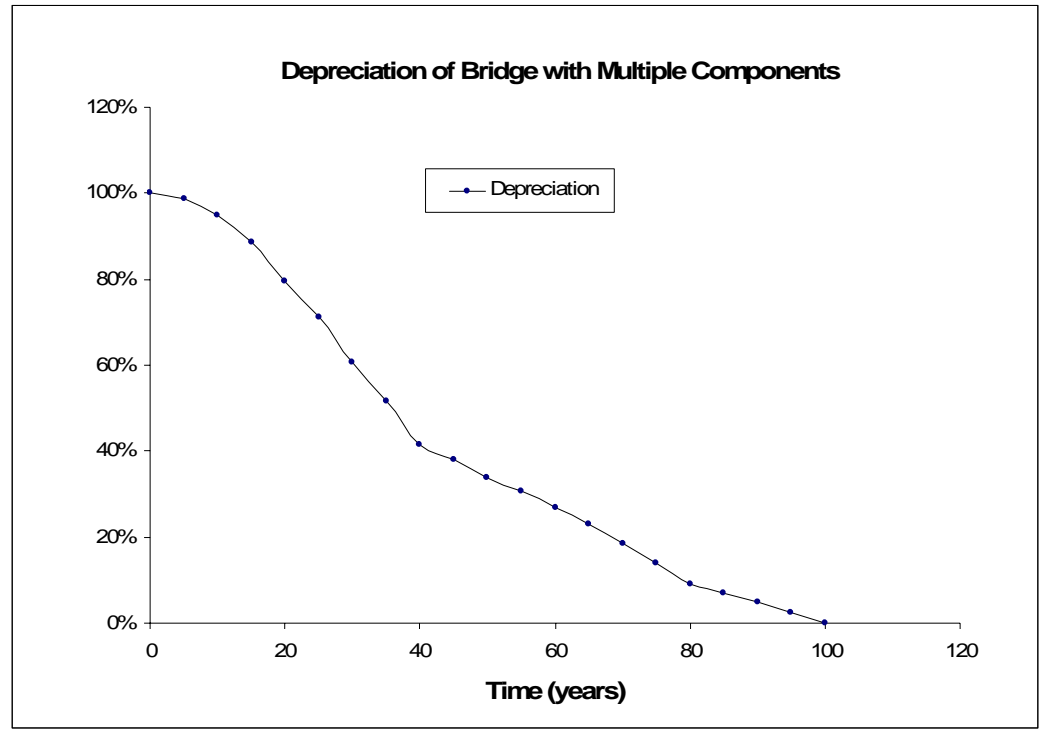

Figure 2. Depreciation of bridge with multiple components and no intervening reinvestment.

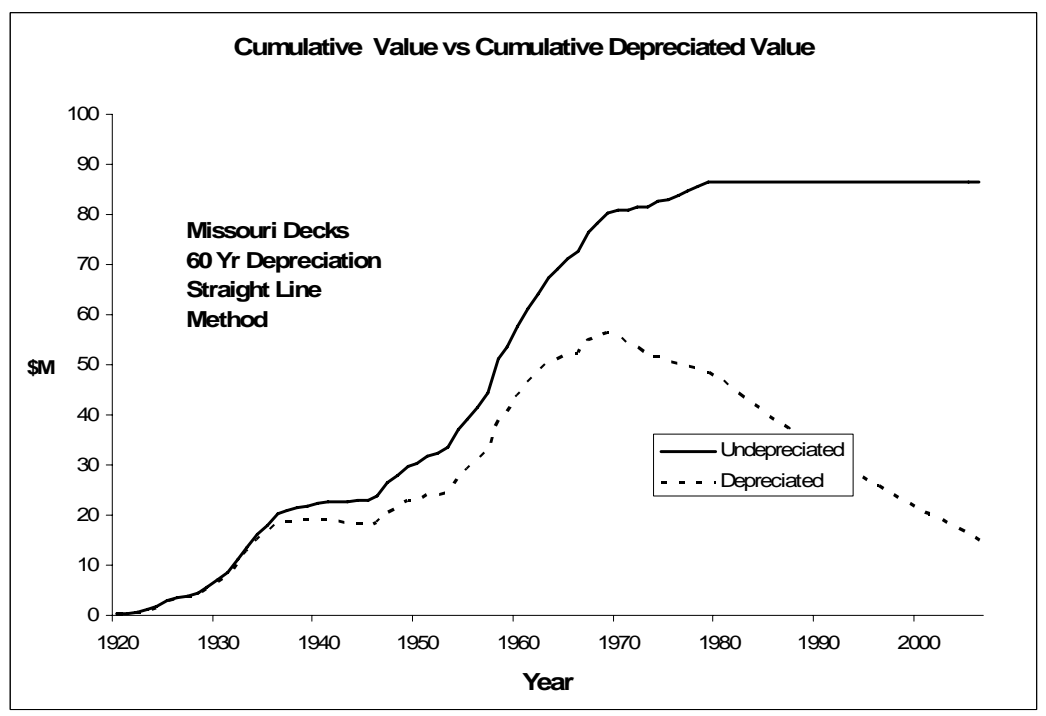

Figure 3. Depreciation of 751 bridge decks in Missouri. 
A further example of Depreciation is offered in a population of 751 bridge decks constructed by the State of Missouri between 1900 and 1979. (Kleywegt, unpubl.) Common to all of these decks is the pressing need to rehabilitate or replace the bridges as part of Missouri's "Safe and Sound 800 Better Bridges by 2012” project.

The undepreciated and depreciated value of this network of bridges is shown in Figure 3 above. An arbitrary fixed value of $\$ 300$ per square metre was used as the constant new value of the decks. The value of the decks depreciates in a straight line from full value to zero in a deemed deck life of 60 years. In this example of real bridges the depreciated value of the network of bridge decks at the present time is less than $20 \%$ of the new value. The idea of modeling a bridge in terms of Depreciation aligns perfectly with the GASB 34 accounting initiative in the US and the analogous PSAB 3150 requirements in Canada.

\subsection{Defects and Damage}

The most compelling reason for further modeling a bridge in terms of Defects and Damage is the simple elegance of only two easily understood definitions that can be applied to every component of a bridge. It is much simpler for an individual to work with two over-arching definitions than a manual full of complex and sometimes conflicting attempts to describe the same concept subjectively. This eliminates perhaps $50 \%$ of the volume of bridge inspection manuals that have extensive, complex and unique language on a by-element and material basis. To illustrate the following example shown below as Table 2. is taken directly from Estes (2003).

Table 2. PONTIS condition state definitions for concrete slabs and beams for observable crack width (w) $(\mathrm{mm})$ in mildly reinforced concrete girders.

\begin{tabular}{lllllll}
\hline Crack Type & None & $\leq 0.8 \mathrm{~mm}$ & $0.8<\mathrm{w} \leq 2$ & $2<\mathrm{w} \leq 2.5$ & $2.5<\mathrm{w} \leq 3$ & $\mathrm{~W}>3 \mathrm{~mm}$ \\
\hline Shear & 1 & 2 & 2 & 3 & 4 & 4 \\
Flexure & 1 & 1 & 2 & 3 & 4 & 4 \\
Diagonal & 1 & 2 & 2 & 3 & 3 & 4 \\
\hline
\end{tabular}

The above table assigns Condition State numbers based on crack width in reinforced concrete girders. The approach, although completely valid, requires exhaustive references to manuals or guides to ensure fidelity to the intent. Is it not substantially easier to think of cracks in girders either as being of no consequence and therefore a Defect, or of structural consequence and therefore Damage?

It is much easier to grasp the concept of a Defect or Damage than it is to apply a more ambiguous and subjective term such as "Fair" or a number that represents a condition state. The quantity of Defects or Damage, even when estimated based on field observation, is inherently more precise than a condition state number that represents a range of possibilities.

\section{CONCLUSIONS}

Current bridge inspection record keeping typically burdens the inspector with referring to a lexicon of sometimes ambiguous and most often subjective language that is difficult to commit to memory. This ambiguity and subjectivity results in mediocrity and significant variability in outcomes.

There is little value in assessing the "goodness" of a bridge. Most inspectors in fact shy away from assigning high ratings to even relatively new bridges. Accordingly, it may be advisable to dispense with tasking bridge inspectors with evaluating how much of a bridge is Excellent or Good.

The concept of Depreciation is well understood. It can be deterministically modeled. The transition of a bridge from Excellent condition to Fair condition using subjective terms is better described and understood by describing the same phenomenon as Depreciation. 
A Defect is a simply understood term that describes relatively benign changes to a bridge component that can not be adequately characterized as Depreciation. Defects are of importance to bridge asset management as they are often a precursor to Damage. The simplicity of the concept should yield improved and more accurate reporting of actual component condition.

Damage is any transformation of a component to a structurally weaker condition. Damage is the most important aspect of data collection during bridge inspection. The term Damage is relatively easy to distinguish from Defect because of the simplicity of both definitions.

Simple definitions and eliminating the task of rating a bridge's "goodness" will facilitate concentrating bridge inspection efforts on exceptions that truly merit attention. The regular and timely recording of Defects and Damage on a component basis will yield a less subjective repository of data that will more precisely reflect the growth of bridge deterioration.

Adopting a "Triple-D" approach to bridge asset management should facilitate the evolution of a more consistent bridge condition metric.

\section{REFERENCES}

AASHTO, 1997. AASHTO Guide for Commonly Recognized (CoRe) Structural Elements American Association of State Highway and Transportation Officials ISBN: 1-56051-046-3

Estes, A.C. \& Frangopol, D.M. 2003. Updating Time-Dependent Reliability of Highway Bridges with Pontis Bridge Management System Inspection Results 9th International Bridge Management Conference Transportation Research Circular Number E-C049: 229-236

Johnson, M.B. 2003. Condition-Based Bridge Asset Valuation 9th International Bridge Management Conference Transportation Research Circular Number E-C049: 149-153

Johnson, M.B., Kerr, R.I., Thompson, T.S., \& Ailaney, R.K. 2006? Bridge Management Experiences of California, Florida, and South Dakota US Department of Transportation Federal Highway Administration FHWA IF-05-040

Kenedi, W. 2004 MTO Bridge Inspection Workshop for MTO Staff and Consultants Bridge Office Ministry of Transportation (Ontario) (not published)

Kleywegt, H.S. 2007. Depreciation Analysis of State of Missouri Bridge Decks (not published)

Moore, M., Phares, B., Graybeal, B., Rolander, D. \& Washer, G. 2001. Reliability of Visual Inspection for Highway Bridges US Department of Transportation Federal Highway Administration FHWA-RD$01-020$

Ontario Ministry of Transportation (MTO) 2000. Ontario Structure Inspection Manual. Ronen House: Toronto

Smith, N \& Silva Filho, L.C.P. 2000 Economic Appraisal in Advanced Bridge Management Systems TRB Transportation Research Circular 498

Thompson, P.D., Ellis, R.M., Hong, K. \& Merlo, T. 2003. Implementation of Ontario Bridge Management System 9th International Bridge Management Conference Transportation Research Circular Number E-C049: 112-127 